\title{
Semiautomated Laser Capture Microdissection of Lung Adenocarcinoma Cytology Samples
}

\author{
Sinchita Roy Chowdhuri ${ }^{\mathrm{a}}$ Jeffrey Hanson ${ }^{\mathrm{a}}$ Jerome Cheng ${ }^{\mathrm{c}}$ \\ Jaime Rodriguez-Canales ${ }^{a}$ Patricia Fetsch ${ }^{a}$ Ulysses Balis ${ }^{c}$ Armando C. Filie ${ }^{a}$ \\ Giuseppe Giaccone $^{b}$ Michael R. Emmert-Buck ${ }^{a}$ Jason D. Hipp ${ }^{c}$ \\ ${ }^{\mathrm{a}}$ Laboratory of Pathology and ${ }^{\mathrm{b}}$ Medical Oncology Branch, National Cancer Institute, Bethesda, Md., and \\ 'Department of Pathology, University of Michigan, Ann Arbor, Mich., USA
}

\section{Key Words}

Semiautomated laser capture microdissection - Spatially invariant vector quantization $\cdot$ Lung adenocarcinoma •

Cytology

\begin{abstract}
Objective: In the past decade molecular diagnostics has changed the clinical management of lung adenocarcinoma patients. Molecular diagnostics, however, is largely dependent on the quantity and quality of the tumor DNA that is retrieved from the tissue or cytology samples. Frequently, patients are diagnosed on cytology specimens where the tumor cells are scattered within the cell block, making selecting for tumor enrichment difficult. In the past we have used laser capture microdissection (LCM) to select for pure populations of tumor cells to increase the sensitivity of molecular assays. This study explores several methods for semiautomated computer-guided LCM. Study Design: Hematoxylin and eosin- or TTF-1-immunostained slides from a pleural effusion cell block with metastatic lung adenocarcinoma were used for LCM with either AutoScan or a recently described pattern-matching algorithm, spatially invariant vector quan-
\end{abstract}

tization (SIVQ), to define morphologic predicates (vectors) to select cells of interest. Results: We retrieved pure populations of tumor cells using both algorithm-guided LCM approaches with slight variations in cellular retrievals. Both methods were semiautomated, requiring minimum technical supervision. Conclusion: In this study we demonstrate the first semiautomated, computer-guided LCM of a cytology specimen using SIVQ and AutoScan, a first step towards the long-term goal of integrating LCM into the clinical cytology-molecular workflow.

Copyright $\odot 2012$ S. Karger AG, Basel

\section{Introduction}

In the past decade the clinical management of lung carcinoma has undergone a paradigm shift, with molecular diagnostics playing a leading role in deciding the course of treatment based on patient-specific molecular profiles [1-3]. The discovery of activating mutations in the tyrosine kinase domain of the epidermal growth factor receptor (EGFR) in a subset of patients with lung adenocarcinoma that correlate with a dramatic therapeutic

\section{KARGER}

Fax +4161306 1234

E-Mail karger@karger.ch

www.karger.com
(C) 2012 S. Karger AG, Basel

0001-5547/12/0566-0622\$38.00/0

Accessible online at:

www.karger.com/acy
Correspondence to: Dr. Jason D. Hipp

Department of Pathology, University of Michigan Health System

M4233A Medical Science I, 1301 Catherine

Ann Arbor, MI 48109-0602 (USA)

E-Mail Jason.hipp@gmail.com 
response to tyrosine kinase inhibitors (TKIs), erlotinib and gefitinib, paved the way for targeted therapy in lung carcinomas [4-10]. A subset of lung adenocarcinoma patients that do not harbor EGFR mutations have mutations in KRAS, a downstream molecule in the EGFR pathway, and have constitutive activation of KRAS and do not respond to treatment by TKIs $[11,12]$. Therefore, molecular diagnostic testing not only plays an important new role in pathologic diagnosis of lung adenocarcinomas but has also become a prerequisite for targeted therapy using TKIs and determining clinical management.

Most patients with lung carcinoma are diagnosed at an advanced stage with either metastatic disease or unresectable tumor that precludes them from surgical resection. A large fraction of these patients are diagnosed on cytology alone, which may be the only material available for molecular testing [13-15]. Molecular diagnostics, however, is limited by the amount of tumor DNA available, and thus the challenge in performing molecular analysis from cytology cell blocks often lies in retrieving meaningful data from small numbers of tumor cells. Unlike histology sections from surgical resections where macrodissection can enrich for tumor DNA content, the heterogeneity of tumor cells in cell blocks usually precludes selecting for tumor cells for enrichment. Hence cell blocks are typically used in their entirety by whole slide scrapes for DNA extraction which include tumor cells as well as benign cells such as lymphocytes, histiocytes, and mesothelium, thus diluting the tumor DNA content and decreasing the sensitivity of the molecular assay.

In recent years, molecular analysis has seen significant advancements through the integration of laser capture microdissection (LCM) into the molecular workflow [1625]. LCM provides a reliable method for selectively isolating tumor cells and has been shown to be effective in increasing the sensitivity of molecular assays using cytology cell blocks [26]. However, LCM requires the technical expertise of a pathologist or cytotechnologist to select for the tumor cells, an effort that can be tedious and time consuming depending on the number of tumor cells required for the molecular assay. In order to more effectively integrate LCM into the clinical workflow in the future, it will be useful to develop a semiautomated process where the pathologist is in a supervisory role and performs a less hands-on technical function.

To date, several studies using immunoguided LCM have been published that use: (1) human operator-based dissection, (2) computer-assisted stain recognition software program targeting, or (3) expression microdissec- tion [27-32]. The first method allows for the selection of specific cell types by aiming the laser at the stained target cells under direct microscopic visualization, whereas the second approach uses a computer algorithm to target cell selection for LCM. In contrast, expression microdissection, a microdissection method on immunotargeting, can be performed in a completely automated fashion or alternatively in concert with a software package such as AutoScanXT (Molecular Devices, Sunnyvale, Calif., USA) to identify stained target cells and then auto-dissect them with minimal supervision. All three approaches are compatible with either immunohistochemistry (IHC) or immunofluorescence to guide the dissection process [27, $28,31]$. Irrespective of the method utilized, the advantage of immunolabeling is the ability to recognize tumor cells based on the staining pattern, allowing a high-throughput, semiautomated method for isolating them with very low contamination from surrounding benign cells. It is important to note, however, that there are two main drawbacks to these procedures. The first is the time, expense, and technical troubleshooting required for the immunostaining step, and the second is the detrimental effect of IHC on molecular recovery, including a reduced DNA yield from immunostained samples, posing a potential limitation of studying cytology cell blocks where the tumor cells are often scant and limited [30].

In contrast, spatially invariant vector quantization (SIVQ) is a recently described pattern-matching algorithm for identification and selection of specific cell types in pathology samples (e.g. prostate cancer, bladder cancer, colon cancer, esophageal cancer, stromal tumors, lymphomas, microorganisms, and breast calcifications) that does not necessarily require immunostaining [3234]. SIVQ is simple to use, requires minimal training, and does not utilize significant computational resources. To perform a search with SIVQ, the pathologist identifies a morphologic pattern of interest (predicate image) and the algorithm then performs an exhaustive search of the entire image to find similar cell types or features. Previously, we integrated SIVQ into the ArcturusXT LCM workflow to enable computer-guided LCM to semiautomate the process and enable more efficient dissections that require less human contact time [32]. In the present study, we demonstrate the first semiautomated, computer-guided LCM of human lung adenocarcinoma cells from pleural effusion cell blocks, using SIVQ and AutoScan on hematoxylin and eosin (H\&E)- and IHC (TTF1)-stained slides, a first step towards the long-term goal of integrating LCM into the clinical cytology-molecular workflow. 


\section{Materials and Methods}

\section{Clinical Sample}

A malignant pleural fluid from a patient with metastatic lung adenocarcinoma was examined. Cytomorphologic evaluation of direct smears and/or cytospins as well as IHC studies (TTF-1 and Napsin A positivity) were performed on a formalin-fixed, paraffin-embedded cell block section confirming the diagnosis. The study was performed under National Cancer Institute Institutional Review Board-approved protocols.

\section{Cytologic and IHC Staining}

The cell block was cut into $4-\mu \mathrm{m}$ sections, mounted on glass slides or Arcturus PEN membrane glass slides (Life Technologies catalog No. LCM0522), and stained with H\&E or with an antibody for TTF-1 to detect the lung tumor cells in the pleural effusion. Following deparaffinization, slides intended for immunostaining were subjected to a microwave antigen retrieval procedure with citrate buffer, pH 6.0 (BioGenex, San Ramon, Calif., USA), and then analyzed on a Nexus Automated Immunostainer (Ventana Medical Systems, Tucson, Ariz., USA) with a primary antibody to anti-TTF-1, clone SPT24 (1:10 dilution; Novocastra/Leica Microsystems, Buffalo Grove, Ill., USA), and the DAB iView detection system (Ventana Medical Systems). The IHC slides were counterstained with hematoxylin. All slides were dehydrated, and no coverslip was applied. The slides were stored in a dry environment protected from direct light until ready for LCM.

\section{AutoScan-LCM}

The AutoScanXT Software Module from Life Technologies is an image analysis program that identifies $\mathrm{H} \& \mathrm{E}$-stained cells/features and immunostained cells of interest. The H\&E- and TTF-1immunostained slides from a single pleural effusion cell block were placed on the platform of the ArcturusXT instrument and a magnification of $\times 10$ was selected. The software was trained on one field of view where the true-positive (tumor cells arranged in an acinar pattern for the H\&E- and the TTF-1-stained adenocarcinoma cells for the IHC) and true-negative cells (background proteinaceous material, mesothelial and inflammatory cells/features) were manually annotated. After training of the algorithm, a separate field of view was selected for analysis which resulted in the creation of a dissection map. A Capsure ${ }^{\mathrm{TM}}$ Macro LCM cap (Life Technologies catalog No. LCM0211) was then placed automatically over the chosen area of the tissue. Once the cells of interest that were highlighted by the software were verified by the user, the machine automatically dissected out the highlighted cells of interest using a near-infrared laser pulse that transferred them onto the LCM cap.

\section{Spatially Invariant Vector Quantization Laser Capture}

Microdissection

For a detailed explanation of the SIVQ-LCM procedure, please see Hipp et al. [32]. Briefly, a picture was taken of an uncoverslipped H\&E slide using a drop of xylene to match the refraction index and thus enhance the microscopic visualization. This image was then imported into SIVQ. A predicate image feature unique to the adenocarcinoma morphology (a portion of cytoplasm and the hyperchromatic irregular nucleus from an acinar structure) was identified and selected. This feature was then used to search the image. Cells that matched the predicate morphology were 'painted' by the algorithm. The 'painted image' was then imported into the ArcturusXT and the AutoScan software was used to identify the paint and draw a corresponding dissection map. A Capsure Macro LCM cap (Life Technologies catalog No.LCM0211) was then placed automatically over this area of the tissue and the machine auto-dissected the highlighted cells using a near-infrared laser pulse that transferred them onto the LCM cap.

For the IHC-stained tissue, a procedure similar to the one described above was used; however, the selected vector contained a portion of the dark brown immunostained nucleus as the predicate image feature.

Finally, LCM procedures using AutoScan on H\&E slides, AutoScan on TTF-1 slides, SIVQ on H\&E slides, and SIVQ on TTF1 slides were compared. For each procedure, LCM efficiency was evaluated in terms of the percentage of target cells identified by the software from the total target cells ('selected cells'), and the percentage of selected cells actually captured on the LCM cap ('retrieved cells'). The percentage of selected cells is a function of the efficiency of the software to identify the target cells. The percentage of retrieved cells depends on the efficiency of LCM to capture the selected cells from the slide, which is a function of several factors including slide preparation conditions such as the type of slide used for LCM (i.e. more efficient with membrane slides, and less efficient with glass slides used in common clinical routine), staining, dehydration, laser parameters, and positioning of the LCM cap.

\section{Results}

\section{AutoScan-LCM H\&E}

An H\&E-stained pleural effusion cell block slide was first analyzed for microdissection using AutoScan. A representative field of view was selected to train the software. The 'ground truth' positive cells (i.e. tumor cells) were annotated as the cells of interest and the 'ground truth' negative cells (mesothelial cells, inflammatory cells, and red blood cells) and features (white background, collagen) were also annotated. The algorithm trained on these features and was then used to analyze a separate field of view within the same slide (fig. 1a). The output of the algorithm is shown in figure $1 \mathrm{~b}$, with the tumor cells annotated in green. While the majority of the tumor cells were identified and annotated, there were also a number of background reactive mesothelial cells that were incorrectly identified as 'tumor', a major drawback to using AutoScan LCM on H\&E slides. The cells annotated in green were then automatically dissected by LCM and are shown in figure 1c. AutoScan was able to identify and select approximately $30-50 \%$ of the tumor cells and 30 $50 \%$ of the selected cells were retrieved by dissection from the glass slide. 


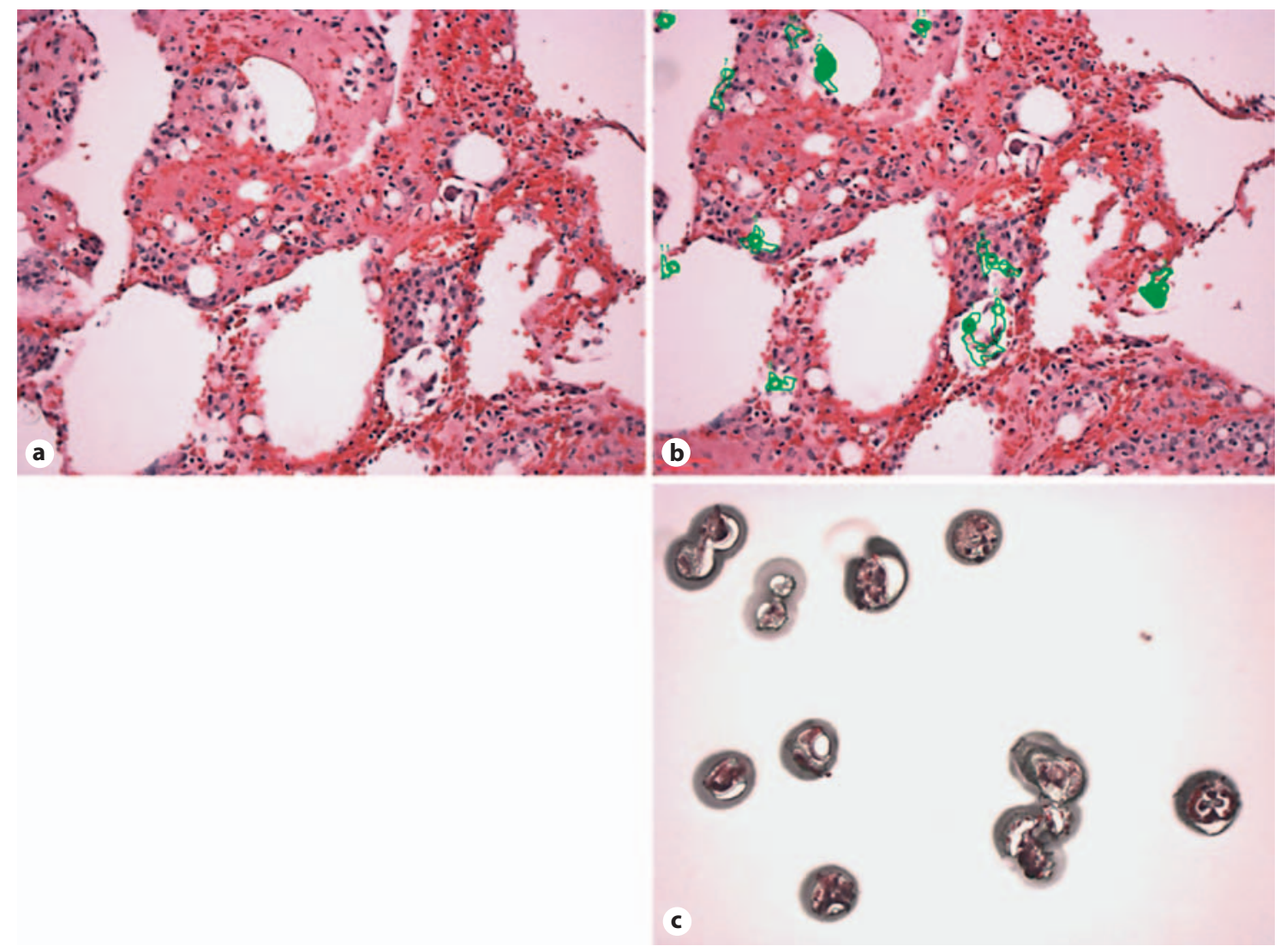

Fig. 1. H\&E-stained section of a malignant pleural effusion cell block microdissected at a $\times 10$ magnification using AutoScan. a Section showing scattered groups of lung adenocarcinoma cells in a background of red blood cells, lymphocytes, mesothelial cells, and histiocytes. b Selection of cells using AutoScan based on morphologic criteria. c View of the LCM cap showing the tumor cells that were microdissected from the background using AutoScan.

\section{AutoScan-LCM IHC (TTF-1)}

For the immunoguided LCM we chose TTF-1 as an immunomarker for the tumor cells in the malignant pleural fluid since the antibody stains lung carcinoma cells and not mesothelial cells or inflammatory cells. A representative field of view was selected to train the software, and the ground truth positive cells (i.e. IHC stained tumor cells) and ground truth negative cells (cells that did not stain) and features (white background and faint nonspecific background staining) were annotated. The algorithm trained on these features was then used to analyze on a separate field of view within the same slide (fig. 2a). The output of the algorithm is shown in figure $2 b$, with the tumor cells painted in blue. These cells were autodissected by LCM and are shown in figure 2c. Approximately $75 \%$ of the TTF-1-stained tumor cells were selected by the algorithm as true tumor cells, which was sig- nificantly higher than when $\mathrm{H} \& \mathrm{E}$ slides were used. After LCM approximately $50 \%$ of the selected cells were successfully retrieved from the glass slide.

\section{Spatially Invariant Vector Quantization-Laser}

Capture Microdissection Hematoxylin and Eosin

SIVQ-LCM was performed on an H\&E-stained pleural effusion cell block slide. The challenge here was to define a predicate morphologic feature that would differentiate adenocarcinoma tumor cells from benign counterparts such as mesothelial cells, a challenge due to their overlapping morphologic features. Selecting hyperchromatic, enlarged nuclei with irregular nuclear membranes did not result in success as the software incorrectly targeted both reactive mesothelial cells and inflammatory cells. Ultimately, we used the acinar formation of glandular structures along with a retraction artifact as a vector 

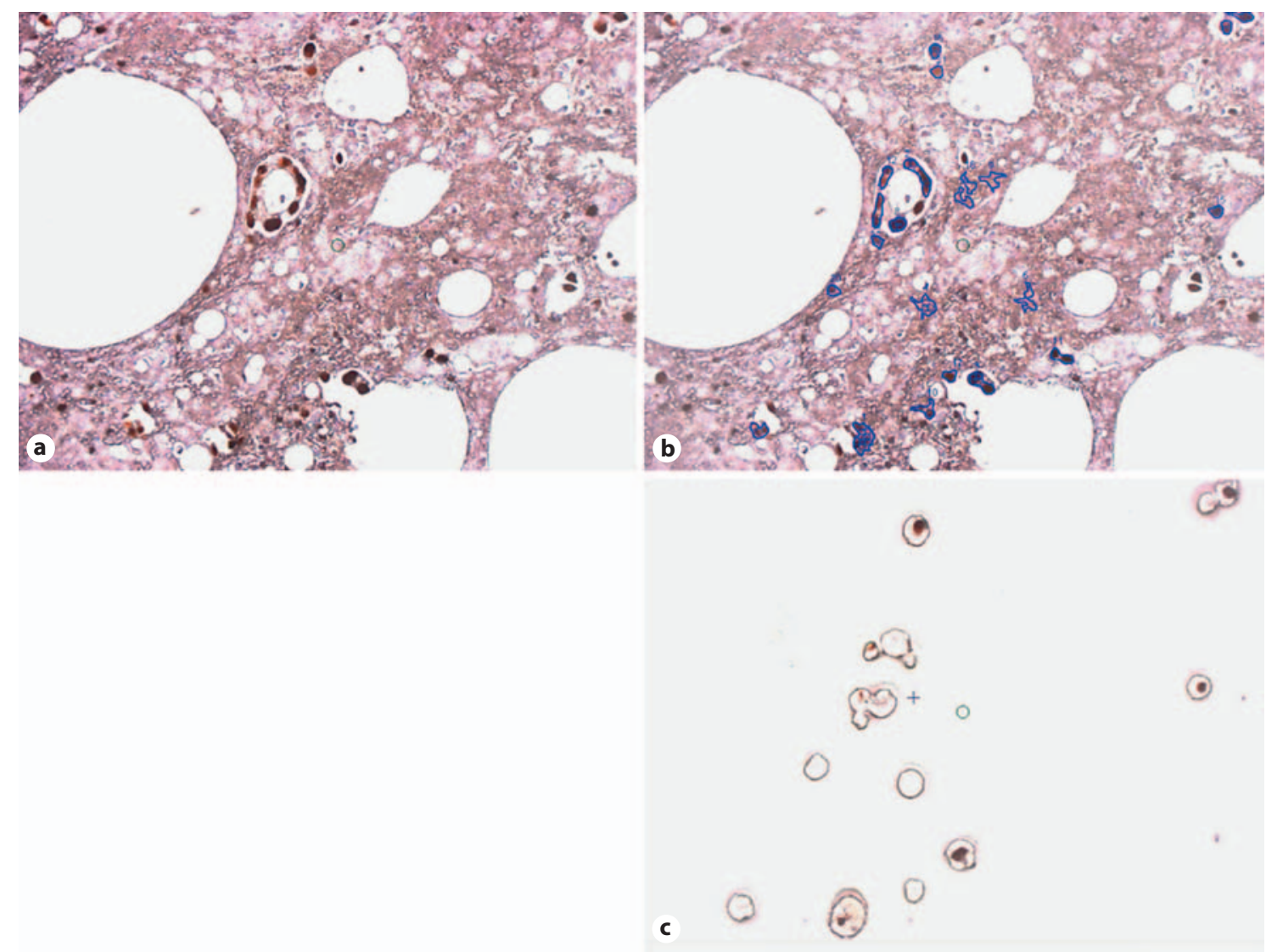

Fig. 2. Immunoguided LCM of a malignant pleural effusion cell block stained for TTF-1 at a $\times 10$ magnification using AutoScan. a Section showing lung adenocarcinoma cells staining for TTF-1 in a background of benign cells that do not stain. b Selection of cells using AutoScan based on cells that stain dark brown. c View of the LCM cap showing the tumor cells that were selected and microdissected from the background using AutoScan.

and were then able to identify clusters of tumor cells with very little contamination from mesothelial or inflammatory cells. Although isolated tumor cells were sometimes missed using this vector, the majority of tumor cells in groups and clusters were identified by SIVQ with no contamination from surrounding benign cells.

Once this suitable vector was selected, a representative field of view was imaged (fig. 3a) and imported into SIVQ. The image was then searched and resultant matches were painted in red (fig. 3b) and imported back into the ArcturusXT, and AutoScan software was used to draw a dissection map and auto-dissect the target cells (fig. 3c, d). All SIVQ identified target cells were manually screened by a pathologist for accuracy prior to microdissection. SIVQ was able to identify and select approximately $50 \%$ of the tumor cells, and $50 \%$ of the selected cells were retrieved from the glass slide.
Spatially Invariant Vector Quantization-Laser Capture Microdissection Immunohistochemistry (TTF-1)

SIVQ-LCM was performed on an IHC-stained (TTF1) pleural effusion cell block slide. A predicate image feature was chosen to recognize the dark brown chromagen (DAB) of cells that expressed TTF-1. Once a suitable vector was selected, a representative field of view was imaged (fig. 4a) and imported into SIVQ. The image was then searched and resultant matches were painted in red (fig. 4b). This image was then imported back into the ArcturusXT and the AutoScan software was used to draw a dissection map for subsequent auto-dissection (fig. 4c, d). All SIVQ-identified target cells were manually screened by a pathologist for accuracy prior to microdissection. The method was able to identify and select approximately $90 \%$ of the tumor cells from the 


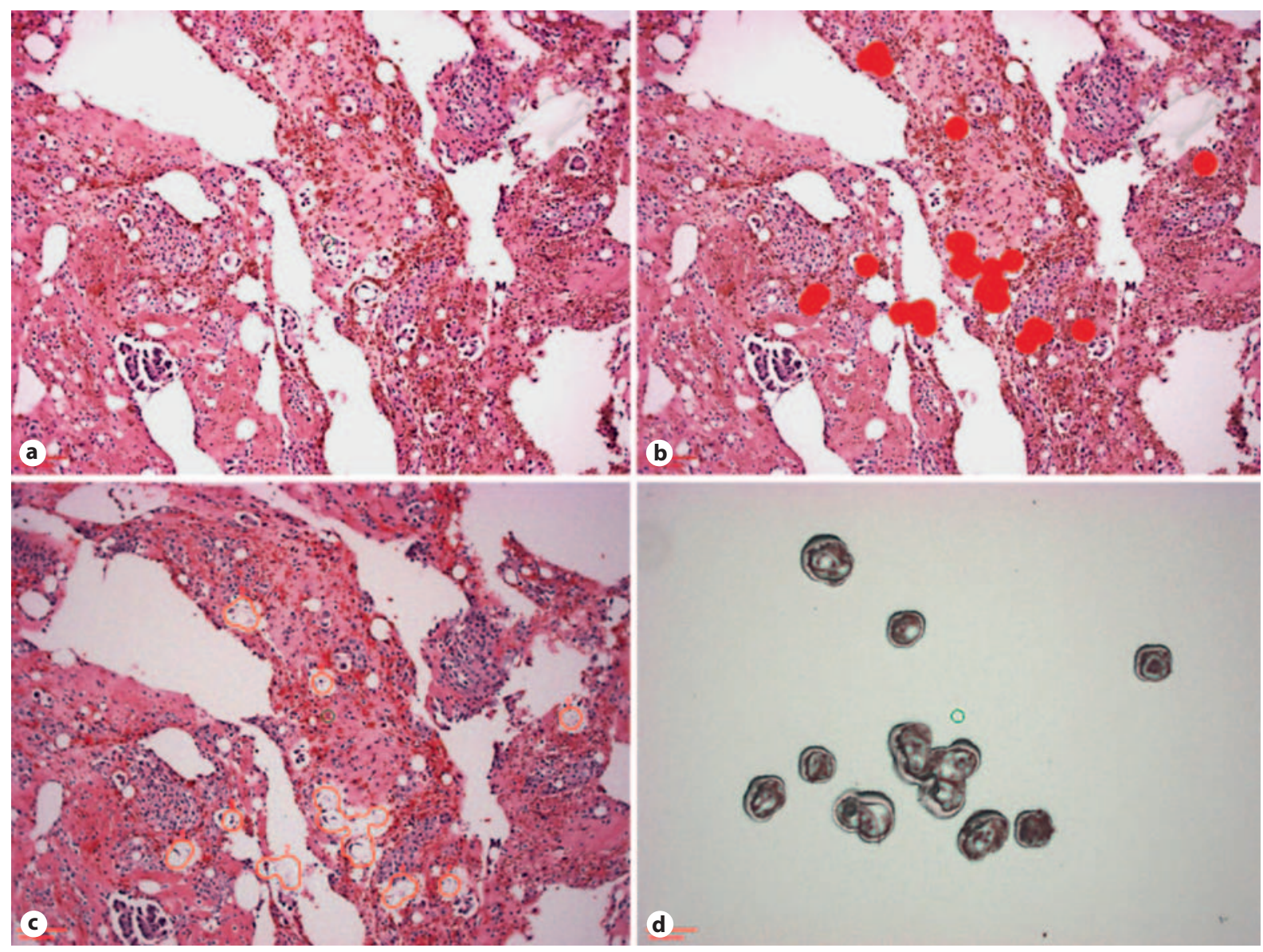

Fig. 3. SIVQ-LCM of an H\&E-stained cell block section of a malignant pleural effusion at a $\times 10$ magnification. a Section showing scattered groups of lung adenocarcinoma cells in a background of red blood cells, lymphocytes, mesothelial cells, and histiocytes. b A vector was chosen to recognize a specific morphologic feature, the acinar structure, to paint the tumor cells and AutoScan was used to create a dissection map. c H\&E section after the microdissection to show the remaining tissue. $\mathbf{d}$ View of the LCM cap showing the tumor cells that were selected and microdissected from the background.

membrane slide, significantly more than the approaches described above, and cell retrieval after LCM was roughly $50 \%$.

\section{Discussion}

Shifting the workflow of LCM into a semiautomatic process with a pathologist or investigator in a supervisory rather than a hands-on technical role will be useful for future integration of LCM into the clinical workflow. Today, a large fraction of lung cancer cases for molecular testing are cytology samples where the tumor cells are often scattered and limited, making macrodissection for tumor enrichment difficult. Therefore, there is a need for developing new methods to isolate tumor cells and increase the sensitivity of molecular assays [26]. Standard LCM on a cytology cell block is often time consuming and requires the technical expertise of a pathologist or cytotechnologist to select tumor cells. In contrast, computer-aided LCM has the potential to reduce or eliminate this rate-limiting step of manual cell selection.

The field of molecular diagnostics is constantly evolving due to rapid advancements in technology. Molecular analysis of clinical specimens is largely dependent on the material available for testing, and a frequent challenge that molecular pathologists face is generating meaningful data from limited patient cells or tissues. Several studies have shown that cytology cell blocks provide an excellent source for molecular testing $[13,14,35]$. In patients 


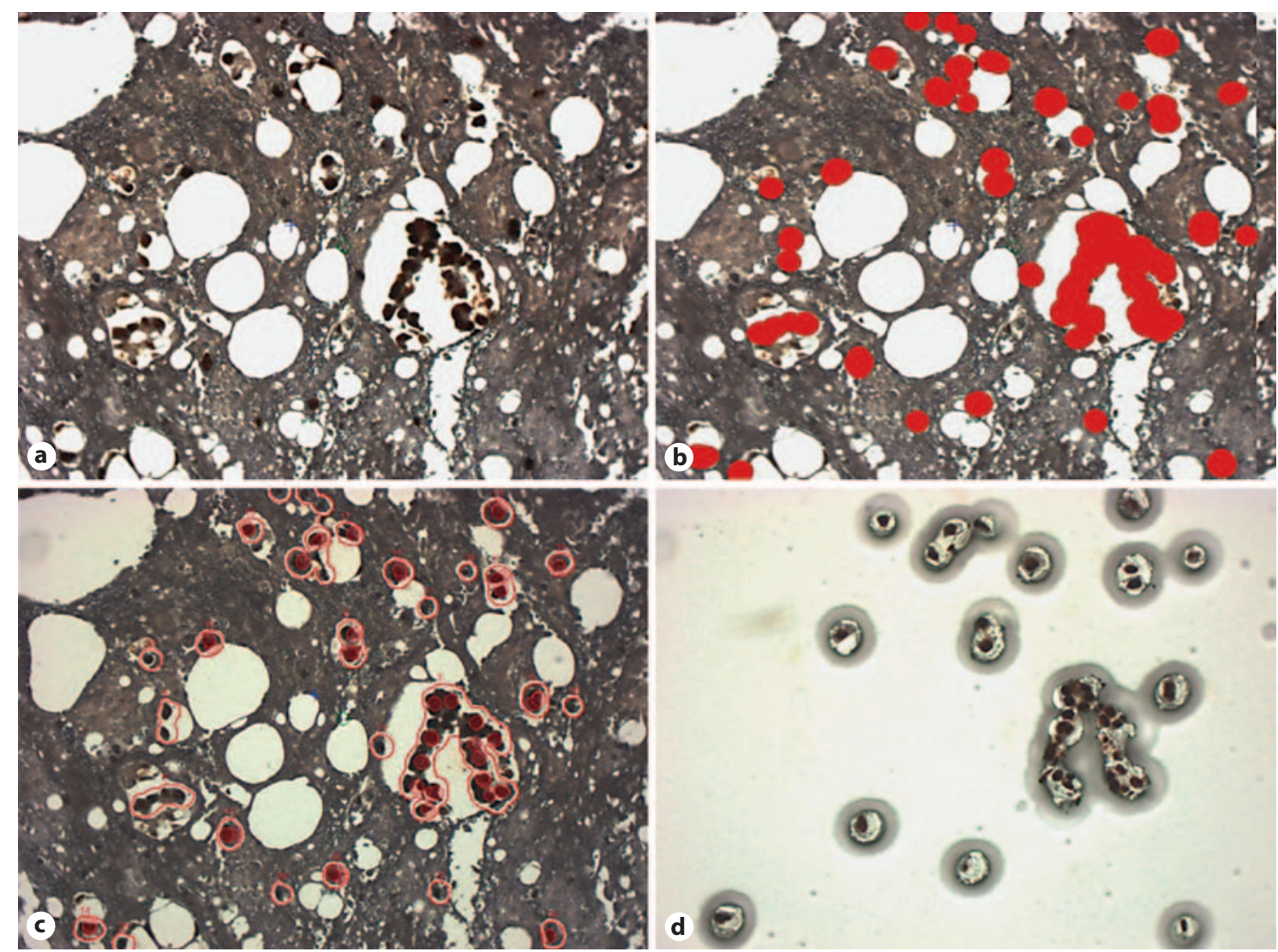

Fig. 4. SIVQ-LCM of a malignant pleural effusion cell block using TTF-1 at a $\times 10$ magnification. a Section showing lung adenocarcinoma cells staining for TTF-1 in a background of benign cells that do not stain. $\mathbf{b}$ A vector was chosen to recognize the dark brown stain of TTF-1-stained cells to paint the tumor cells. c The paint was recognized by AutoScan and a dissection map was created to microdissect the selected cells. $\mathbf{d}$ View of the LCM cap showing the tumor cells that were microdissected from the background.

with advanced stage unresectable lung cancer, for example, cytology samples may be the only specimen available for molecular testing, and molecular diagnostics plays an important prognostic role in treatment of these patients.

In a previous study, we showed that using standard laser capture to isolate small numbers of tumor cells (approx. 50) in cytology formalin-fixed paraffin-embedded cell blocks was adequate for EGFR and KRAS mutation testing in patients with lung adenocarcinoma [26]. Furthermore, the technique enabled the identification of mutations that were not otherwise observed using standard cell scraping, thus allowing additional patients to benefit from treatment. In the current study we explored various computer-aided LCM (via image analysis algorithms) approaches in an effort to semiautomate the microdissection process to facilitate the more rapid retrieval of tumor cells and reduce the time and effort required of the pathologist.

\section{Limitations}

The greatest challenge in working with $\mathrm{H} \& \mathrm{E}$-stained pleural effusions of lung adenocarcinoma cells is the morphologic overlap with reactive mesothelial cells. Often times, IHC staining for TTF-1, which specifically stains the lung tumor cells but not mesothelial cells, is needed for confirmation of the diagnosis. Thus, the capability of computer algorithms is similar to that of a pathologist identifying these cells on H\&E alone. While this may be sufficient in some cases, it is not always adequate so we decided to explore other technical approaches. Performing image analysis on an IHC-stained pleural effusion cell block section is an easier image analysis task because it primarily requires differentiation based on texture alone. In addition, using an antibody that specifically stains the lung tumor cells makes the 
selection of the target population more specific and eliminates contamination from nonpulmonary nontumor cells. Thus, computer-aided IHC (TTF-1) LCM ensured we identified the majority of tumor cells (single cells as well as clusters of tumor cells) and increased our specificity. While this provided a high-throughput semiautomated method to isolate tumor cells for molecular assays, the downside is that IHC can negatively affect the DNA recovered from tissue sections [30].

The amount of DNA retrieved from IHC slides is suboptimal when compared to unstained slides or H\&E slides and can pose a challenge when analyzing patient cases that have a limited number of cells. Studies from our group and others have shown that, although the quantity of DNA retrieved is reduced, the quality and integrity is not affected and DNA can be successfully amplified by PCR [30] with no obvious difference in performance between IHC-stained and unstained samples. However, in the context of clinical molecular assays one does have to be cautious of introducing false-positive results when amplifying very small amounts of DNA. Further studies will be necessary to interrogate molecular assays using microdissected cells from these various methods to ensure they produce accurate and consistent results.

Another limitation in the current approach was the use of glass slides. The clinical workflow utilizes charged glass slides to strengthen the attachment of the tissue, and overcoming this effect is a challenge of implementing LCM in the clinical setting. However, we mitigated this difficulty by employing membrane-coated slides designed for LCM that enabled nearly complete retrieval of target cells.

The choice of IHC stain is also a challenge since none of the currently available antibodies is entirely specific for lung adenocarcinoma cells. TTF-1 and Napsin A are the most commonly used antibodies; however, some lung adenocarcinomas are negative for these markers and require the use of a more global adenocarcinoma marker such as BerEP4 or even cytokeratins. TTF-1 can also stain benign pneumocytes, while Napsin A can stain alveolar macrophages, and thus can negate the ability to procure a pure population of tumor cells based entirely on staining properties when dealing with FNA samples. The future use of IHC-guided LCM will ultimately depend on the staining pattern of the individual tumor, the specimen source (lung FNA vs. FNA of metastasis vs. pleural effusion), and the types of cells present in the sample.

\section{SIVQ and AutoScan: Strengths and Weaknesses}

AutoScan is a commercially available software system that can be purchased with the ArcturusXT instrument. SIVQ is a software program developed at the University of Michigan that is publically available to academic collaborators ( $\sim 10$ groups across the country are currently validating and using the algorithm).

One of the major differences between AutoScan and SIVQ is that AutoScan requires a training step in that the user has to iteratively select the true-positive and truenegative cells and then test this on subsequent images to optimize the algorithm. In contrast, SIVQ does not require training. Rather, it is a pattern-matching algorithm where a predicate feature is selected by the user and then utilized for subsequent searching using iterative testing and real-time evaluation of match quality.

AutoScan also differs from SIVQ in that it does not require as much morphology expertise. Rather, cells of interest are simply selected and annotated. SIVQ requires identification of an archetypal morphologic feature and a trained histopathologist has a significant advantage in identifying such predicate features based on diagnostic criteria. As an example, one could use the prominent cherry red nucleoli as a predicate feature for the identification of Hodgkin's lymphoma [33].

The advantage of both AutoScan and SIVQ is that they do not require significant computer programming/image processing expertise. Both algorithms use a graphical user interface enabling 'pointing and clicking' of cells and features. Command line programming, often necessary with algorithms run in MATLAB, is not required for use.

\section{Future Directions}

The work presented here is just one aspect of the larger process of automating LCM for integration into the clinical workflow; however, these advancements are a significant step forward in reducing the time and labor often required for LCM. Looking ahead, additional steps will need to be further optimized, such as improving cell retrieval when glass slides are used, optimizing the sensitivity and specificity of tumor cell identification, and improving the DNA yield from IHC-stained sections. Finally, it is likely that future molecular diagnostic assays will include expression-based measurements of mRNA, miRNA, and proteomes, not just DNA testing [37]. Cell purity will be at a premium for these future personalized medicine assays since even a small percentage of nontarget cells can compromise expression-based results. In this context, the development and incorporation of computerized tools for cell selection represent an important 
step towards an automatic microdissection of clinical samples for molecular diagnosis compatible with the high-throughput demands of the clinical workflow, requiring just supervision by the pathologist or the cytotechnologist. Thus, we are hopeful the advancements in the current study will ultimately be useful for a wide range of patient-based diagnostic and prognostic tests.

\section{Conclusion}

Accurate identification of patients whose tumors harbor actionable DNA mutations is a significant clinical demand and a reason for implementation of LCM in the cytology-molecular workflow. Here we explored different methods of automating LCM with the aid of computer programs for image analysis to isolate lung adeno- carcinoma cells from cytology cell block sections, with the goal of rapid and high-throughput microdissection of tumor cells for mutation detection in patients with limited cytologic material.

\section{Acknowledgement}

This work was supported in part by the NCI's Center for Cancer Research in the Intramural Program at NIH.

\section{Disclosure Statement}

Michael Emmert-Buck is an inventor on all NIH-held patents covering LCM technology and receives royalty-based payments through the NIH Technology Transfer Program.

\section{References}

$\checkmark 1$ Eberhard DA, Johnson BE, Amler LC, Goddard AD, Heldens SL, Herbst RS, Ince WL, Janne PA, Januario T, Johnson DH, Klein P, Miller VA, Ostland MA, Ramies DA, Sebisanovic D, Stinson JA, Zhang YR, Seshagiri S, Hillan KJ: Mutations in the epidermal growth factor receptor and in kras are predictive and prognostic indicators in patients with non-small-cell lung cancer treated with chemotherapy alone and in combination with erlotinib. J Clin Oncol 2005;23:59005909.

-2 Jackman DM, Miller VA, Cioffredi LA, Yeap BY, Janne PA, Riely GJ, Ruiz MG, Giaccone G, Sequist LV, Johnson BE: Impact of epidermal growth factor receptor and kras mutations on clinical outcomes in previously untreated non-small cell lung cancer patients: results of an online tumor registry of clinical trials. Clin Cancer Res 2009;15:5267-5273.

-3 West H, Lilenbaum R, Harpole D, Wozniak A, Sequist L: Molecular analysis-based treatment strategies for the management of nonsmall cell lung cancer. J Thorac Oncol 2009; 4:S1029-S1039, quiz S1041-S1022.

4 Pao W, Miller V, Zakowski M, Doherty J, Politi K, Sarkaria I, Singh B, Heelan R, Rusch V, Fulton L, Mardis E, Kupfer D, Wilson R, Kris M, Varmus H: EGF receptor gene mutations are common in lung cancers from 'never smokers' and are associated with sensitivity of tumors to gefitinib and erlotinib. Proc Natl Acad Sci USA 2004;101:13306-13311.

5 Lynch TJ, Bell DW, Sordella R, Gurubhagavatula $S$, Okimoto RA, Brannigan BW, Harris PL, Haserlat SM, Supko JG, Haluska FG, Louis DN, Christiani DC, Settleman J, Haber DA: Activating mutations in the epidermal growth factor receptor underlying responsiveness of non-small-cell lung cancer to gefitinib. N Engl J Med 2004;350:2129-2139.

-6 Paez JG, Janne PA, Lee JC, Tracy S, Greulich H, Gabriel S, Herman P, Kaye FJ, Lindeman N, Boggon TJ, Naoki K, Sasaki H, Fujii Y, Eck MJ, Sellers WR, Johnson BE, Meyerson M: EGFR mutations in lung cancer: correlation with clinical response to gefitinib therapy. Science 2004;304:1497-1500.

$\checkmark 7$ Janne PA, Engelman JA, Johnson BE: Epidermal growth factor receptor mutations in non-small-cell lung cancer: implications for treatment and tumor biology. J Clin Oncol 2005;23:3227-3234.

8 Han SW, Kim TY, Hwang PG, Jeong S, Kim J, Choi IS, Oh DY, Kim JH, Kim DW, Chung DH, Im SA, Kim YT, Lee JS, Heo DS, Bang YJ, Kim NK: Predictive and prognostic impact of epidermal growth factor receptor mutation in non-small-cell lung cancer patients treated with gefitinib. J Clin Oncol 2005;23:2493-2501.

-9 Mok TS, Wu YL, Thongprasert S, Yang CH, Chu DT, Saijo N, Sunpaweravong P, Han B, Margono B, Ichinose Y, Nishiwaki Y, Ohe Y, Yang JJ, Chewaskulyong B, Jiang H, Duffield EL, Watkins CL, Armour AA, Fukuoka M: Gefitinib or carboplatin-paclitaxel in pulmonary adenocarcinoma. N Engl J Med 2009;361:947-957.

10 Rosell R, Taron M, Reguart N, Isla D, Moran T: Epidermal growth factor receptor activation: how exon 19 and 21 mutations changed our understanding of the pathway. Clin Cancer Res 2006;12:7222-7231.

11 Pao W, Wang TY, Riely GJ, Miller VA, Pan Q, Ladanyi M, Zakowski MF, Heelan RT, Kris
MG, Varmus HE: Kras mutations and primary resistance of lung adenocarcinomas to gefitinib or erlotinib. PLoS Med 2005;2:e17.

-12 Massarelli E, Varella-Garcia M, Tang X, Xavier AC, Ozburn NC, Liu DD, Bekele BN, Herbst RS, Wistuba, II: Kras mutation is an important predictor of resistance to therapy with epidermal growth factor receptor tyrosine kinase inhibitors in non-small-cell lung cancer. Clin Cancer Res 2007;13:2890-2896.

13 Malapelle U, Bellevicine C, Zeppa P, Palombini L, Troncone G: Cytology-based gene mutation tests to predict response to antiepidermal growth factor receptor therapy: a review. Diagn Cytopathol 2011;39:703-710.

14 Travis WD, Rekhtman N, Riley GJ, Geisinger KR, Asamura H, Brambilla E, Garg K, Hirsch FR, Noguchi M, Powell CA, Rusch VW, Scagliotti G, Yatabe Y: Pathologic diagnosis of advanced lung cancer based on small biopsies and cytology: a paradigm shift. J Thorac Oncol 2010;5:411-414.

15 Rivera MP, Detterbeck F, Mehta AC: Diagnosis of lung cancer: the guidelines. Chest 2003; 123:129S-136S.

16 Bonner RF, Emmert-Buck M, Cole K, Pohida T, Chuaqui R, Goldstein S, Liotta LA: Laser capture microdissection: molecular analysis of tissue. Science 1997;278:1481-1483.

17 Burgess JK, Hazelton RH: New developments in the analysis of gene expression. Redox Rep 2000;5:63-73.

18 Iyer EP, Cox DN: Laser capture microdissection of Drosophila peripheral neurons. J Vis Exp 2010, DOI: 10.3791/2016.

19 Craven RA, Banks RE: Laser capture microdissection for proteome analysis. Curr Protoc Protein Sci 2003; chapter 22:unit 22.3. 
20 Mustafa D, Kros JM, Luider T: Combining laser capture microdissection and proteomics techniques. Methods Mol Biol 2008; 428:159-178.

-21 Lawrie LC, Curran S: Laser capture microdissection and colorectal cancer proteomics. Methods Mol Biol 2005;293:245-253.

22 Charboneau L, Paweletz CP, Liotta LA: Laser capture microdissection. Curr Protoc Cell Biol 2001; chapter 2:unit 2.5.

23 Bichsel VE, Liotta LA, Petricoin EF 3rd: Cancer proteomics: from biomarker discovery to signal pathway profiling. Cancer J 2001;7: 69-78.

-24 Callagy G, Jackson L, Caldas C: Comparative genomic hybridization using DNA from laser capture microdissected tissue. Methods Mol Biol 2005;293:39-55.

-25 Kurihara Y, Ghazizadeh M, Bo H, Shimizu $\mathrm{H}$, Kawanami O, Moriyama Y, Onda M: Genome-wide screening of laser capture microdissected gastric signet-ring cell carcinomas. J Nihon Med Sch 2002;69:235-242.

-26 Chowdhuri SR, Xi L, Pham TH, Hanson J, Rodriguez-Canales J, Berman A, Rajan A, Giaccone G, Emmert-Buck M, Raffeld M, Filie AC: Egfr and kras mutation analysis in cytologic samples of lung adenocarcinoma enabled by laser capture microdissection. Mod Pathol 2012;25:584-555.
27 Fend F, Emmert-Buck MR, Chuaqui R, Cole $\mathrm{K}$, Lee J, Liotta LA, Raffeld M: ImmunoLCM: laser capture microdissection of immunostained frozen sections for mrna analysis. Am J Pathol 1999;154:61-66.

28 Fend F, Kremer M, Quintanilla-Martinez L: Laser capture microdissection: methodical aspects and applications with emphasis on immuno-laser capture microdissection. Pathobiology 2000;68:209-214.

29 Eltoum IA, Siegal GP, Frost AR: Microdissection of histologic sections: past, present, and future. Adv Anat Pathol 2002;9:316-322.

30 Tangrea MA, Mukherjee S, Gao B, Markey SP, Du Q, Armani M, Kreitman MS, Rosenberg AM, Wallis BS, Eberle FC, Duncan FC, Hanson JC, Chuaqui RF, Rodriguez-Canales J, Emmert-Buck MR: Effect of immunohistochemistry on molecular analysis of tissue samples: implications for microdissection technologies. J Histochem Cytochem 2011; 59:591-600.

-31 Eberle FC, Hanson JC, Killian JK, Wei L, Ylaya K, Hewitt SM, Jaffe ES, Emmert-Buck MR, Rodriguez-Canales J: Immunoguided laser assisted microdissection techniques for DNA methylation analysis of archival tissue specimens. J Mol Diagn 2010;12:394-401.

32 Hipp J, Cheng J, Hanson JC, Yan W, Taylor P, $\mathrm{Hu}$ N, Rodriguez-Canales J, Tangrea MA, Emmert-Buck MR, Balis U: SIVQ-aided laser capture microdissection: a tool for highthroughput expression profiling. J Pathol Inform 2011;2:19.
33 Hipp JD, Cheng JY, Toner M, Tompkins RG, Balis UJ: Spatially invariant vector quantization: a pattern matching algorithm for multiple classes of image subject matter including pathology. J Pathol Inform 2011;2:13.

34 Hipp J, Smith SC, Cheng J, Tomlins SA, Monaco J, Madabhushi A, Kunju LP, Balis UJ: Optimization of complex cancer morphology detection using the SIVQ pattern recognition algorithm. Anal Cell Pathol (Amst) 2012;35:41-50.

35 Smouse JH, Cibas ES, Janne PA, Joshi VA, Zou KH, Lindeman NI: EGFR mutations are detected comparably in cytologic and surgical pathology specimens of nonsmall cell lung cancer. Cancer Cytopathol 2009;117: 67-72.

36 Cheng J, Hipp J, Monaco J, Lucas DR, Madabhushi A, Balis UJ: Automated vector selection of SIVQ and parallel computing integration MATLAB: innovations supporting large-scale and high-throughput image analysis studies. J Pathol Inform 2011;2:37.

37 Bibbo M: How technology is reshaping the practice of nongynecologic cytology: frontiers of cytology symposium. Acta Cytologica 2007;51:123-152. 